\title{
EL ÉXITO ACADÉMICO EN EL PRIMER AÑO DE LA CARRERA DE INGENIERÍA INDUSTRIAL Y SU VÍNCULO CON FACTORES ACADÉMICOS PREVIOS
}

\author{
Academic Success in the First Year of the Industrial Engineering Course \\ and its Link with Previous Academic Factors
}

José Alberto Vilalta Alonso ${ }^{1}$

ORCID: 0000-0001-7505-8918

María Julia Becerra Alonso ${ }^{1}$

ORCID: 0000-0003-3503-1491

Rogelio Lau Fernández ${ }^{1}$

ORCID: 0000-0003-2731-2381

${ }^{1}$ Universidad Tecnológica de La Habana José Antonio Echeverría, La Habana, Cuba.

Correos: jvilalta@ind.cujae.edu.cu; mjuliab@ind.cujae.edu.cu; lau@ceis.cujae.edu.cu

Recibido: 19/07/2018

Aceptado: 31/03/2020

Resumen: En la Facultad de Ingeniería Industrial de la Universidad Tecnológica de La Habana ingresa una cantidad significativa de estudiantes, de los que se dispone un volumen de datos que pueden ser analizados para contribuir a gestionar el proceso de formación de manera intencionada. En este estudio se utilizan técnicas de estadística descriptiva que permiten extraer información útil y relevante de los datos educacionales que son registrados como entradas o resultados del proceso de formación de profesionales. El objetivo de este trabajo es analizar la información obtenida de los estudiantes de primer año académico de la carrera, matriculados en los cursos académicos entre el 2012 y el 2017, para la mejora de su rendimiento académico. Se muestra el análisis de un conjunto de datos para estudiar posibles correlaciones entre factores influyentes, lo que permite apreciar una disminución en la promoción y en la eficiencia académica. Para el procesamiento de los datos educacionales se utilizaron técnicas y paquetes computacionales estadísticos. Los resultados obtenidos indican la relevancia que tienen los niveles de ingreso de los estudiantes en primer año para lograr el éxito académico.

Palabras clave: éxito académico; factores académicos; datos educacionales; indicadores de ingreso; desempeño académico. 
Abstract: A significant number of students enter the Industrial Engineering Faculty of the Universidad Tecnológica de La Habana, from which a volume of data is available and can be analyzed to contribute to the management of the educational process in an intentional way. In this study, descriptive statistical techniques are used to extract useful and relevant information from the educational data that are recorded as inputs or results of the process of training professionals. The objective of this work is to analyze the information obtained from students in the first academic year of the career, enrolled in academic courses between 2012 and 2017, in order to improve their academic performance. It shows the analysis of a set of data to study possible correlations between influencing factors, which allows us to appreciate a decrease in promotion and academic efficiency. For the processing of the educational data, statistical techniques and computer packages were used. The results obtained indicate the relevance of first-year student admission levels for academic success.

Keywords: academic success; academic factors; educational data; admission indicators; academic performance.

\section{Introducción}

Entre los aspectos a tener en cuenta para garantizar el rendimiento académico en las universidades está el desempeño estudiantil y los factores que afectan los resultados esperados, por lo que su estudio y análisis son imprescindibles. Los factores influyentes y el peso que tienen varían de una carrera a otra; de ahí la importancia analizar aquellos datos que aporten información de interés sobre el desempeño del estudiante desde su entrada a la institución académica.

La literatura reconoce una amplísima variedad de factores o variables que impactan el rendimiento académico y ponen en riesgo la permanencia del alumno en la enseñanza de pregrado. Se mencionan el horario de los cursos, el tamaño de los grupos, las políticas educativas, los métodos de evaluación, las características del profesor, la aptitud intelectual del estudiante, el tipo de colegio donde terminó la enseñanza previa, el modo de ingreso al programa de estudio, el entorno sociocultural, su situación económica, la edad, la modalidad de estudio (Parra et al., 2012; Soria-Barreto y Zúñiga-Jara, 2014; Urrutia et al., 2014).

Muchos autores (Parra et al., 2012; González, 2015; Quintana y Stive, 2015; Kinsumba, 2017) dan cuenta del bajo nivel de aprovechamiento en el primer año de las carreras universitarias y del costo financiero, social y en el orden individual que representa el fracaso escolar en estudiantes que ingresan al sistema universitario. La noción de fracaso escolar, estudiada por diferentes autores (Díaz Peralta, 2008; González y Sánchez, 2015), tiene en el caso de las instituciones universitarias cubanas la peculiaridad de que no necesariamente un alumno suspenso debe abandonar la universidad. El reglamento de organización docente (Ministerio de Educación 
Superior, 2017) establece que los estudiantes matriculados en las modalidades de Curso por Encuentro y Curso Diurno, cuando desaprueban hasta dos asignaturas del año, podrán matricularlas como arrastre en el siguiente curso siempre que no sean aquellas que constituyen requisitos de ingreso (Historia, Español, Matemática). Para los autores, el éxito académico es una manera más operacional de ver el rendimiento académico y se entiende como la relación entre el proceso de aprendizaje y sus resultados tangibles en valores predeterminados. De ahí que pueda expresarse en una calificación, cuantitativa o cualitativa, que refleje un nivel de aprendizaje y el logro de objetivos preestablecidos.

Según Zeegers (2004), entre los factores que parecen tener efectos directos y medibles en el desempeño académico el más prominente es el rendimiento previo. Este autor asegura que existe una gran convergencia entre las investigaciones en cuanto a que es una variable clave en la predicción del rendimiento futuro.

Son de interés para este trabajo aquellas variables relacionadas con la enseñanza precedente y de las que se reconoce su impacto en el desempeño académico, lo que justifica su estudio y análisis posterior. El examen diagnóstico sobre conocimientos generales de las áreas de la ciencia (Urrutia et al., 2014; González y Sánchez, 2015); los intereses en torno a la elección de la carrera (Urrutia et al., 2014; Soria-Barreto y Zúñiga-Jara, 2014; González y Sánchez, 2015; Quintana y Stive, 2015) y el malestar psicológico (Urrutia et al., 2014) son algunos de los más reconocidos.

La anticipación del estado futuro de los acontecimientos a partir de un pronóstico o de otro tipo de análisis es una práctica habitual en muchas áreas del conocimiento. En la enseñanza universitaria tiene un impacto incalculable porque, entre otras razones, facilita determinar la probabilidad de deserción. En el campo de la investigación pedagógica puede encontrarse con frecuencia, dada la necesidad de encontrar alternativas de trabajo diferenciado con los estudiantes.

La utilización adecuada de la información para mejorar el rendimiento académico conduce a asumir un grupo de conceptos, seleccionar variables de análisis y determinar sus vínculos. En este trabajo será imprescindible asumir la definición de rendimiento y eficiencia para el entorno académico, así como su contextualización a la educación superior cubana. Otros conceptos valiosos para el análisis serán los de éxito académico y datos educacionales.

El rendimiento académico es entendido como el resultado de un proceso educativo que puede medirse en términos cuantitativos y cualitativos, que sirve para retroalimentar a los individuos y a las instituciones sobre el logro de los objetivos que se establecieron previamente y 
que expresa la relación entre el proceso de aprendizaje y sus resultados tangibles en valores predeterminados (Guzmán, 2012; Parra et al., 2012).

Una manera de expresar el rendimiento académico en el contexto universitario es el éxito, el cual se puede entender como el alcance, por parte del estudiante, de los objetivos de instrucción establecidos por la institución universitaria formadora y expresados en un número cuando se ha alcanzado el nivel de aprobado. Este concepto puede expresarse de diferentes maneras en función de los intereses de los investigadores; por ejemplo, se ha considerado como éxito académico pasar de un año para el siguiente (Kinsumba, Lau y Becerra, 2017).

El sistema universitario cubano se caracteriza por instituciones que, en su mayoría, abarcan una gran cantidad de carreras, tanto del ámbito técnico (ingenierías, arquitectura) como de las humanidades, ciencias básicas y pedagógicas. La excepción son las universidades de ciencias médicas, solo dedicadas a este campo, algunas universidades pedagógicas y la Universidad Tecnológica de La Habana José Antonio Echeverría (CUJAE), solo dedicada a la formación de ingenieros y arquitectos.

Aunque el acceso a la universidad es gratuito, los estudiantes que opten por ello deben someterse a tres exámenes de ingreso: Matemática, Español e Historia de Cuba. Las calificaciones obtenidas en esos exámenes y las notas de la enseñanza preuniversitaria permiten conformar un escalafón, en la que cada una de ellas aporta el $50 \%$ del total. El estudiante confecciona una lista de diez opciones, teniendo en cuenta sus preferencias y sus posibilidades. Las plazas se asignan según el orden del escalafón hasta completar la cantidad ofertada por carreras.

Un parámetro por excelencia para medir la calidad de las instituciones universitarias cubanas es la eficiencia académica, concepto que establece la relación entre la cantidad de estudiantes que se gradúa y la cantidad total de matriculados cinco cursos atrás, que es la duración de la mayoría de las carreras universitarias en Cuba. El Ministerio de Educación Superior, además, establece el término eficiencia vertical. Con este vocablo se especifica el desempeño estudiantil en un curso académico y se obtiene al multiplicar los valores de la promoción de cada uno de los años de ese mismo periodo (Milán, Ruiz y Fraga, 2013).

El reto que representa incrementar la eficiencia académica de una carrera es alcanzable si se cuenta con datos que permitan la toma de decisiones en general o la predicción del éxito académico en particular. El uso de técnicas estadísticas permite obtener información relevante de los datos identificados. 
Los datos pueden ser considerados como el soporte físico de la información; constituyen uno de los recursos clave de las organizaciones y, si son defectuosos, pueden afectar la eficiencia y la eficacia de estas. La importancia de los datos está en su capacidad de asociarse dentro de un contexto para convertirse en información, lo que depende del uso que se les da y de las herramientas de análisis que se emplean para extraer dicha información. Los datos educacionales, por ejemplo, aportan información relevante para valorar el proceso de enseñanza-aprendizaje, concretamente el rendimiento académico del alumno (Vilalta, Heredia y Flores, 2012; Heredia, Rodriguez y Vilalta, 2014; Quintana y Stive, 2015).

La educación universitaria contempla un amplio registro del perfil de cada alumno desde su entrada y cada profesor puede hacer uso de ella si cuenta con herramientas para su gestión e interpretación. La existencia de los datos por sí solos no genera información de interés para la gestión del proceso formativo. Sin embargo, su análisis desde una perspectiva psicopedagógica favorece su selección como indicadores. Es conveniente identificar asociaciones entre variables que inciden en el éxito del estudiante con vistas a favorecer la eficiencia del proceso formativo y mejorar el autoconocimiento de la institución y la gestión de sus procesos. Esta práctica puede sensibilizar a los docentes con el uso de la información relevante debidamente registrada y realizar un acompañamiento del desempeño del alumno de forma más intencionada.

\section{Materiales y métodos}

En este estudio se utilizan técnicas de estadística descriptiva que permiten extraer información útil y relevante de los datos educacionales que son registrados en el proceso de formación de profesionales en la Facultad de Ingeniería Industrial de la Universidad Tecnológica de La Habana José Antonio Echeverría. Este centro tiene la misión de contribuir a la transformación e integración sinérgica del Sistema de Dirección y Gestión para el desarrollo sostenible de la sociedad cubana con liderazgo nacional y prestigio internacional en el campo de la Ingeniería Industrial (Infante, 2015).

En los últimos cinco años el ingreso a la Facultad de Ingeniería Industrial se ha caracterizado por los altos valores en los índices académicos de sus estudiantes. Sin embargo, hay una buena parte de ellos que ingresan con malos resultados en la prueba de ingreso de Matemática, lo que pudiera condicionar su éxito en la carrera y, en consecuencia, la eficiencia académica, debido a la importancia de esta materia en los estudios de ingeniería. 
Ante esta situación adquiere gran importancia analizar variables mediante el uso de técnicas estadísticas que permitan predecir el éxito académico en estudiantes de primer año y propiciar un trabajo diferenciado por parte de los profesores.

El presente trabajo muestra el análisis de un conjunto de datos para estudiar posibles asociaciones tomando como referencia los cursos del 2012 al 2017, donde se notó una disminución en la promoción y en la eficiencia académica. El análisis de datos requiere seleccionar variables y determinar los métodos estadísticos que faciliten la obtención de informaciones relevantes.

Por cada estudiante se dispone de un grupo de datos al momento de la matrícula. Los de mayor interés para el trabajo, y que están disponibles en la Secretaría de la Facultad, son: el índice académico con que ingresa a la universidad, la opción en que se seleccionó la carrera, las notas obtenidas en las pruebas de ingreso y la puntuación obtenida al finalizar la enseñanza precedente (escalafón). Se puede acceder a esos datos mediante el software Sistema de Gestión de la Nueva Universidad (SIGENU), el cual permite la gestión de la información referente al plan de proceso docente, matrículas e inscripciones por asignaturas y registros de estudiantes.

Teniendo en cuenta el reconocimiento en la bibliografía consultada, el contexto universitario cubano y la información disponible, se consideraron un conjunto de variables potencialmente determinantes del éxito académico de los estudiantes de primer año de la carrera de Ingeniería Industrial:

- Índice académico. Representa el rendimiento del alumno en el nivel de enseñanza precedente (nivel medio superior), por lo que genera una expectativa con respecto al desempeño en la institución universitaria. Constituye uno de los requisitos para acceder a los estudios universitarios, en tanto promedia los resultados obtenidos en las asignaturas de los diferentes años del referido nivel.

- Opción en que se escogió la carrera (Opción). Describe la preferencia por la carrera elegida y el interés en su estudio. Demanda una madurez vocacional y una orientación profesional efectiva. Es el resultado de elegir entre diez opciones para realizar estudios universitarios.

- Nota de Matemática en prueba de ingreso (Matemática). Representa el resultado de uno de los tres exámenes que constituyen requisito de entrada a los estudios universitarios (Matemática, Español e Historia de Cuba). Los estudios de ingeniería demandan saberes vinculados a la Matemática: solo en el primer año de la carrera de Ingeniería Industrial el alumno recibe 256 horas dedicadas a estos contenidos a fin de desarrollar un pensamiento lógico, heurístico y algorítmico. Además, constituye un precedente esencial para el aprendizaje de la Física y la Matemática Aplicada. 
- Escalafón. Es el promedio del índice académico y las notas en las pruebas de ingreso. Es un indicador que se toma en cuenta dentro del sistema de ingreso a una carrera en Cuba con el que se establece un ordenamiento. Se calcula sobre la base de 100 puntos, de los cuales el $50 \%$ corresponde al promedio de las calificaciones obtenidas en la enseñanza precedente y el otro $50 \%$ se le atribuye al promedio de las calificaciones obtenidas en los tres exámenes de ingreso. Es una manera rápida de apreciar la congruencia entre el rendimiento del alumno en la enseñanza media superior y los resultados en una evaluación con un rigor superior.

- Nota de la asignatura Matemática I en el primer semestre (Matemática I). Representa el resultado obtenido en esta materia, una vez matriculado en la carrera. Con la consideración de las notas en la asignatura de Matemática I, en particular, se reconoce la ruptura que se produce con la entrada del alumno a la enseñanza universitaria. Hay un cambio en la organización docente, en la complejidad de las tareas de aprendizaje, incluso en la implicación personal, por lo que un análisis del rendimiento académico requiere incorporar un factor o variable que contemple el desempeño del estudiante ya formando parte del proceso de enseñanza aprendizaje de la educación superior (González y Sánchez, 2015; Quintana y Stive, 2015). Autores como Zamora y Díaz (2008) se refieren a discontinuidades didácticas entre la enseñanza media, media superior y la universidad, y su efecto en el rendimiento de los alumnos.

Los rangos de las variables descritas se presentan en la Tabla 1. Téngase en cuenta que en el caso de las variables índice académico, Matemática y escalafón el rango se ha restringido a las exigencias del ingreso a la educación superior.

Tabla 1

Variables consideradas y sus rangos

\begin{tabular}{cc}
\hline Variable & Rango \\
\hline Índice académico & $60-100$ \\
\hline Opción & $1,2, \ldots, 10$ \\
\hline Matemática & $60-100$ \\
\hline Escalafón & $60-100$ \\
\hline Matemática I & $2,3,4,5$ \\
\hline
\end{tabular}

Fuente: Elaboración propia. 
De la multiplicidad de factores que pueden afectar el rendimiento académico en estudiantes de primer año se seleccionaron estos porque tienen un reconocimiento en la literatura especializada, reflejan el contexto cubano contemporáneo en carreras de ingeniería y se derivan de datos disponibles y de fácil consulta.

Los factores seleccionados consideran tanto elementos que reflejan el nivel de entrada de los estudiantes y que caracterizan el ingreso, como el desempeño del estudiante bajo la influencia de la impronta universitaria. Por ende, proporcionan información útil acerca de los procesos involucrados en el rendimiento académico. Se emplearon técnicas de estadística descriptiva para la descripción numérica de las principales variables involucradas en el estudio y análisis de correlación con el objetivo de observar el grado de relación lineal existente entre estas.

\section{Resultados}

Se tomaron como referencia para el análisis los datos de los estudiantes que ingresaron a la Facultad de Ingeniería Industrial entre los cursos académicos 2012-2013 y 2016-2017. Para cada uno de los cursos se realizó un análisis descriptivo de las variables índice académico, Matemática y escalafón, además de evaluar el grado de correlación (de Spearman) entre estas y el porcentaje de alumnos agrupados por rangos de notas. Se tuvo en cuenta solo a los estudiantes que realizan exámenes de ingreso (provienen del preuniversitario), excluyéndose del análisis otras fuentes de ingreso, por su poco aporte al comportamiento general del grupo.

Desde el curso 2012-2013 hasta el curso 2016-2017 ingresaron a la carrera por la vía antes mencionada unos 650 estudiantes. Entre el $65 \%$ y el $72 \%$ seleccionó como primera opción la carrera de Ingeniería Industrial (ver Figura 1), lo que muestra que de manera general son estudiantes que entran con un alto nivel de motivación inicial. Esto, sumado a que más de la tercera parte proviene del preuniversitario vocacional de ciencias exactas, hace que el nivel de partida de los estudiantes sea relativamente alto (González y Sánchez, 2015; Secretaría Docente, 2016, 2017). 


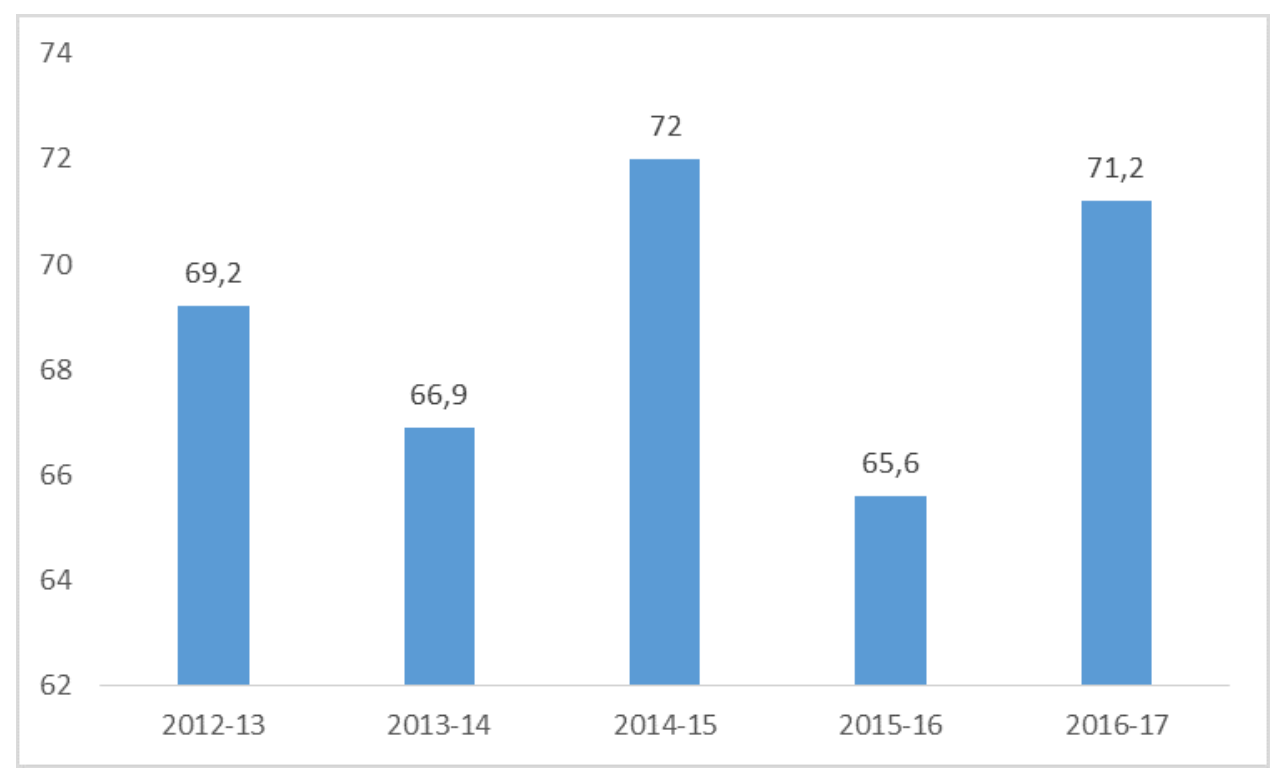

Figura 1. Porcentaje de estudiantes que seleccionan la carrera como primera opción.

Fuente: Secretaría Docente (2017)

Lo dicho se confirma con el hecho de que entre el 77 y el $97 \%$ de los estudiantes tiene un índice académico igual o superior a 95 puntos, de un máximo de 100 (González y Sánchez, 2015; Secretaría Docente, 2016, 2017).

Sin embargo, este alto nivel de entrada de los estudiantes que ingresan a la carrera, y que pudiera augurar un alto nivel de éxito académico, entra en contradicción con los resultados del escalafón —en el que ese porcentaje de estudiantes con 95 o más puntos de índice académico se reduce a entre el 20 y el $63 \%$ - así como con los resultados del examen de Matemática, para el que está entre un 32 y el 58 \% (González y Sánchez, 2015; Secretaría Docente, 2016, 2017). Un resumen de esta información se puede apreciar en la Figura 2.

Sin dudas, y aunque la tendencia ha sido ligeramente a la mejora, los resultados de los exámenes de ingreso y en particular el de Matemática están por debajo de lo esperado de acuerdo con el índice académico de los estudiantes y muestran deficiencias en la preparación de los estudiantes al ingresar en la carrera.

Esta situación tiene un impacto en el éxito de los estudiantes para enfrentar el primer año de la carrera. Lo que se confirma con el hecho de que hay una correlación positiva entre las notas del examen de ingreso de Matemática $(r=0,358, p=0,000)$ y el escalafón $(r=0,41 ; p=0,000)$ con 
la nota de Matemática I en el primer semestre del primer año (Infante, 2015). No se ha considerado en este estudio preliminar el efecto indirecto de la asociación entre la nota del examen de ingreso de Matemática con la nota de Matemática I a través del escalafón.

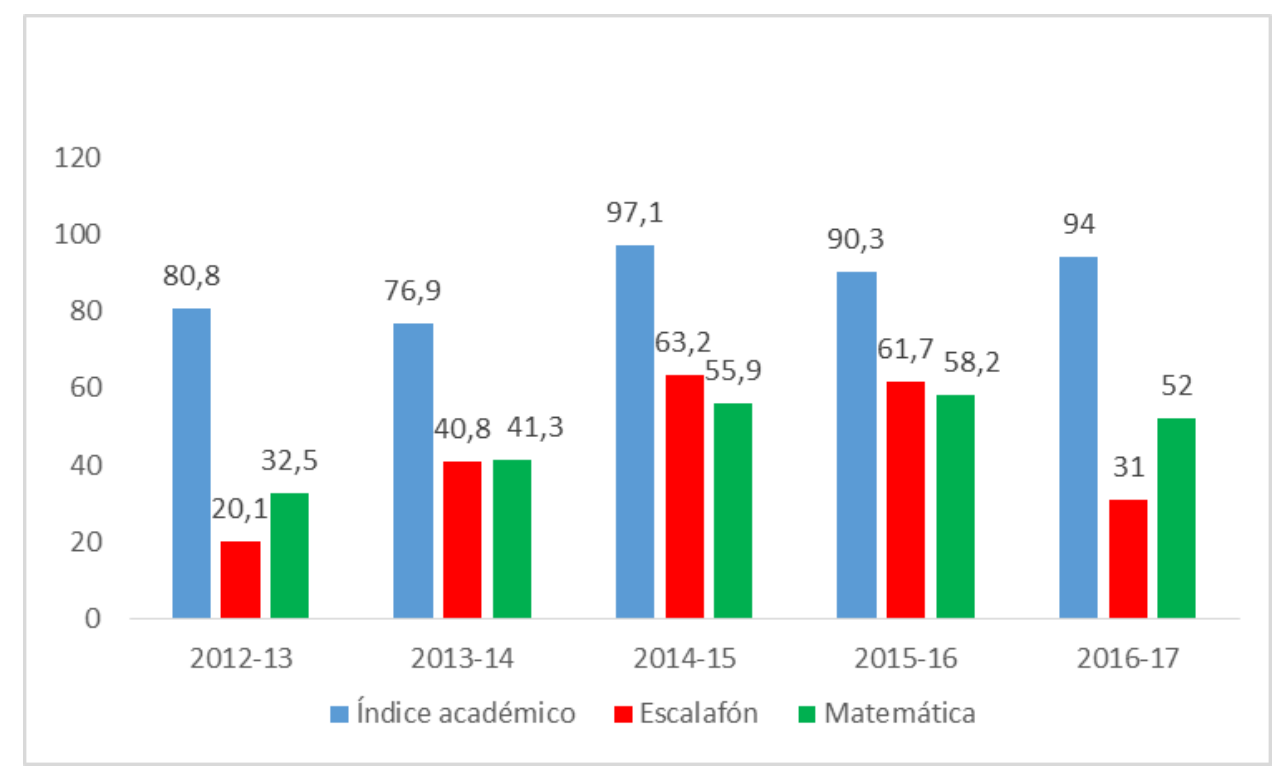

Figura 2. Porcentaje de estudiantes con más de 95 puntos de Índice académico, escalafón y Matemática. Fuente: Secretaría Docente (2017)

Los estudiantes con baja nota en el examen de ingreso de Matemática y bajo resultado en el escalafón tienen una alta probabilidad de tener malos resultados en Matemática I. Debe tenerse en cuenta que Matemática I es la asignatura de peores resultados en el año, con una nota promedio alrededor de los 3,5 puntos (el máximo de la escala es 5) y con el $50 \%$ de los estudiantes, aproximadamente, con 3 puntos de nota final (González y Sánchez, 2015).

En el gráfico de la Figura 3 se muestra el porcentaje de aprobados en cada año académico durante el periodo 2012-2017. En Cuba los estudios de primer ciclo se estructuran en años académicos, en los que todos los estudiantes matriculados deben vencer el conjunto de asignaturas que conforman cada año. En la Figura 3 se observa con regularidad que un grupo de estudiantes que logran vencer el primer año no lo consiguen en el segundo, algo que no ocurre en los restantes años académicos. Es decir, durante el periodo analizado los peores resultados de la carrera ocurren en el segundo año. 
Las asignaturas responsables de esta situación son, en mayor medida, Física II y Matemática III, con porcentajes de aprobados que rondan el $45 \%$ y con nota promedio alrededor de 3 puntos (González y Sánchez, 2015), como se puede ver en el gráfico de la Figura 4.

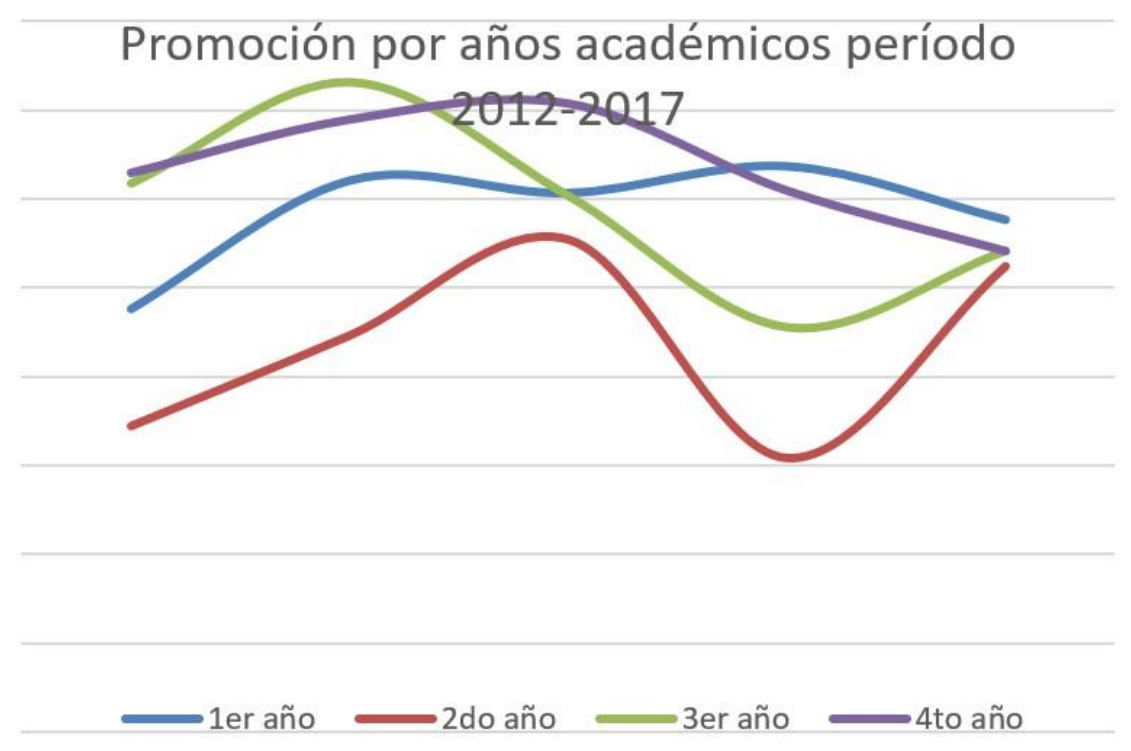

Figura 3. Promoción total desde primero a cuarto año. Fuente: Secretaría Docente (2017).

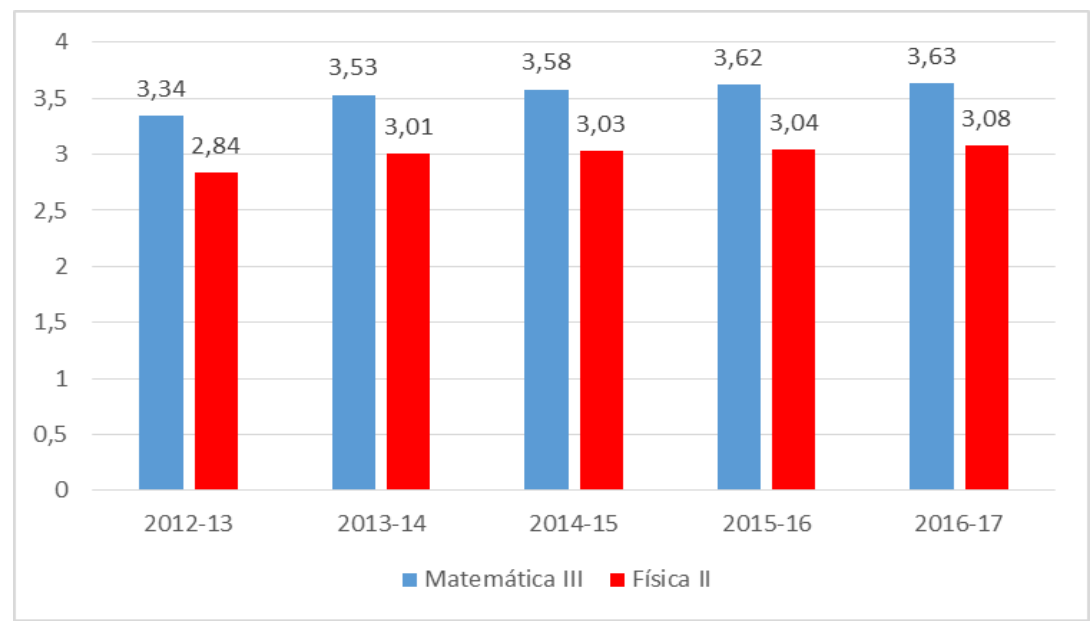

Figura 4. Notas promedio en Matemática III y Física II. Fuente: Secretaría Docente (2017). 
Otros estudios sugieren que está situación está condicionada por los resultados del ingreso. Hay una correlación positiva entre los resultados de Matemática I (condicionados por el ingreso) con la Matemática III ( $\mathrm{r}=0,42 ; \mathrm{p}=0,000)$ y con la Física III $(\mathrm{r}=0,47 ; \mathrm{p}=0,000)$ (Infante, 2015; (González y Sánchez, 2015; Quintana y Stive, 2015; Vilalta, Heredia y Flores, 2012). Esto significa que un estudiante con ingreso deficiente tiene altas probabilidades de tener malos resultados en Matemática I y posteriormente en Matemática III y Física II. En la figura 5 se muestra la matriz de correlación calculada para las variables de interés.

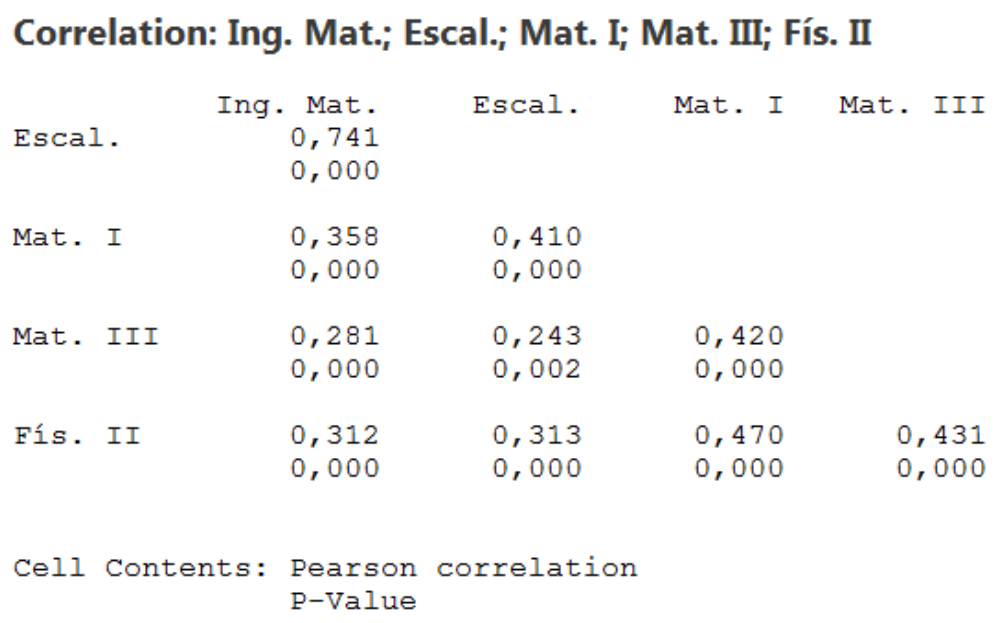

Figura 5. Matriz de correlación entre las variables, calculada con el software Minitab 17.

Fuente: Elaboración propia

\section{Discusión de resultados}

Los análisis realizados con la información disponible sugieren la importancia de los indicadores de ingreso de los estudiantes, dados fundamentalmente por el escalafón y las notas del examen de ingreso de Matemática, por su impacto en las posibilidades de éxito académico.

Los datos muestran que el comportamiento en matemáticas de los estudiantes que solicitan la carrera en primera opción no difiere en gran medida del comportamiento general. Por ejemplo, en el curso 2012-2013, la nota media en Matemática I de todos los estudiantes fue de 3,546 puntos, mientas que la de los que la pidieron en primera opción fue de 3,553. En el caso de Matemática II fue de 3,3881 contra 3,3802 y para Matemática III de 3,125 contra 3.131. Algo similar ocurre en los demás cursos. 
Este comportamiento se puede explicar porque muchos de los estudiantes que no seleccionan la carrera en primera opción seleccionaron como primeras opciones otras ingenierías, lo que condiciona que, desde este punto de vista, no haya grandes diferencias.

Como se expuso, hay una correlación positiva entre estos resultados de ingreso y las asignaturas definitorias en primer año, y entre estas y las de segundo. Esto sugiere que las probabilidades de un estudiante de superar el segundo año, el de peores resultados en la carrera, están condicionadas, en buena medida, por los resultados de los indicadores del ingreso (índice académico, nota de prueba de ingreso en Matemática).

En la Figura 6 se muestra con líneas continuas el vínculo entre las variables correlacionadas (relación directa) y con líneas discontinuas otras asociaciones cuyas correlaciones no fueron calculadas, pero que se supone que tienen un vínculo. El valor de esta información es alertar al sistema educativo de posibles fisuras que generen ineficiencias y que pueden no ser tan evidentes como cuando se calculan las correlaciones. No se tienen en cuenta los efectos indirectos combinados de las variables por no considerarlos relevantes en este análisis preliminar.

Se puso en manos de los docentes información relevante sobre sus estudiantes con respecto a las asignaturas con más dificultades y las relaciones entre ellas, lo que ha posibilitado la realización de acciones oportunas, tanto a nivel individual como colectivo, en aras de la obtención de mejores resultados.

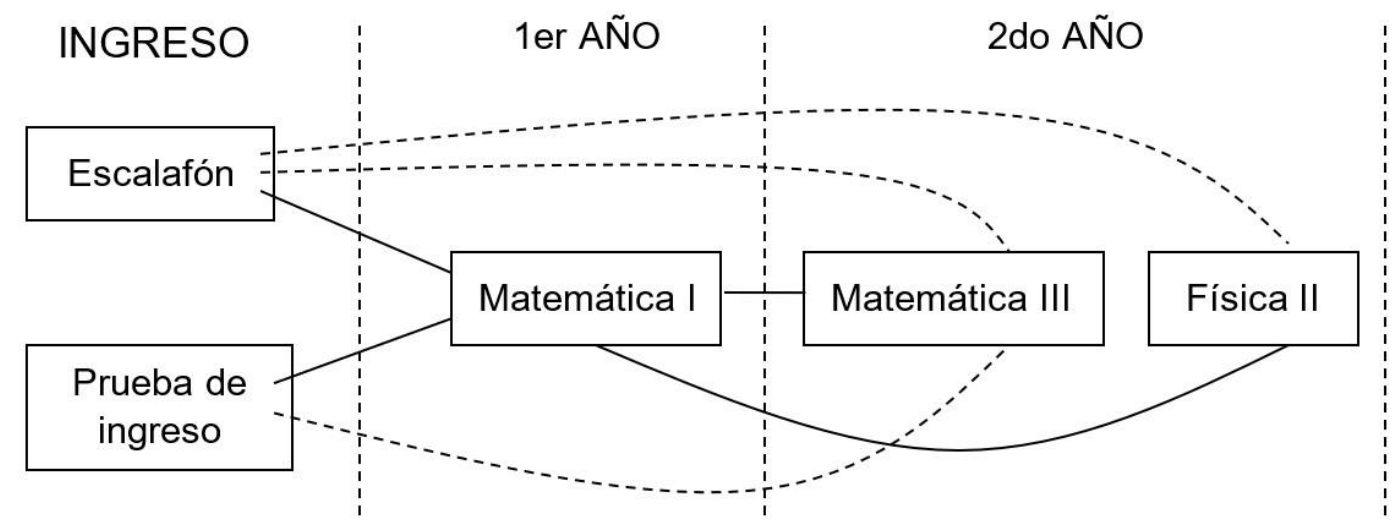

Figura 6. Relaciones directas e indirectas entre variables. Fuente: Elaboración propia

Ha sido importante el uso de esta información para tomar decisiones y brindar un tratamiento diferenciado a los estudiantes con mejores resultados, tanto para su selección como 
alumnos ayudantes, ${ }^{1}$ la integración a grupos de investigación y la asignación de tareas de manera particular (López et al., 2014). Los resultados obtenidos dan mayor precisión a variables relacionadas con el éxito académico, como puede ser indicadores del ingreso, y retroalimentan a las partes interesadas (sistema educativo precedente, directivos y profesores de primer año) sobre deficiencias en sus concepciones.

Teniendo en cuenta lo antes expuesto, para mejorar el éxito académico de los estudiantes de primer año se podría realizar un conjunto de actividades dirigidas a una mejor preparación, en el centro de las cuales debe estar, sin dudas, un fuerte trabajo metodológico a todos los niveles: asignaturas, disciplina, colectivo de año y carrera.

Es conveniente destacar que estas experiencias han sido tomadas en cuenta en el diseño del nuevo Plan de Estudios E, que debe comenzar a regir en el curso 2017-2018 y que establece retos superiores por cuanto descansa más en la gestión del conocimiento por parte de los estudiantes, con fuerte apoyo del claustro de profesores, y donde los niveles de ingreso deben tener una mayor importancia, al disminuirse la cantidad de años de estudios en la carrera.

No se tuvieron en cuenta factores que la literatura asume que impactan en el rendimiento académico, si bien no se desconoce su importancia. La selección de factores requiere no solo contar con la información exacta y relevante, sino que se inserte en las prioridades de la institución docente.

\section{Conclusiones}

El análisis de información relevante sobre los estudiantes de primer año de la Facultad de Ingeniería Industrial mostró un grupo de cuatro variables, relacionadas con factores académicos previos, que pueden estar incidiendo en el rendimiento.

Los resultados obtenidos indican el fuerte impacto que tienen los indicadores de ingreso de los estudiantes en primer año para lograr el éxito académico.

\footnotetext{
${ }^{1}$ Los alumnos ayudantes son estudiantes que, a partir de su disposición y sus buenos resultados académicos, son seleccionados para apoyar a los profesores en una o varias asignaturas. Realizan tareas complementarias a su plan de estudio, tales como impartir clases, atender a estudiantes y participar en proyectos de investigación. La figura de alumno ayudante está contemplada en el Reglamento de Trabajo Docente y Metodológico de la Educación Superior (Ministerio de Educación Superior, 2018).
} 
La obtención de los resultados de esta investigación no hubiera sido posible sin el registro minucioso de datos y la obtención de información relevante a través de la aplicación de técnicas estadísticas en apoyo a los requerimientos de los sistemas modernos de gestión.

Hay otros factores que pueden incidir en el desempeño académico de los estudiantes en los primeros años de la carrera y que no fueron considerados, tales como el nivel académico de los padres, la edad, el sexo, la lejanía de la residencia al centro de estudios, entre otros.

\section{Referencias}

Díaz Peralta, C. (2008). Modelo conceptual para la deserción estudiantil universitaria chilena. Estudios Pedagógicos, $34(2), 65-86$.

González, Y., y Sánchez, R. L. (2015). Metodología para el análisis y predicción del comportamiento del proceso de formación en la Facultad de Ingeniería Industrial (Trabajo de diploma). Universidad Tecnológica de La Habana José Antonio Echeverría, La Habana, Cuba.

Heredia J., Rodríguez A., y Vilalta J. (2014). Predicción del rendimiento en una asignatura empleando la regresión logística ordinal. Estudios Pedagógicos, 40(1), 145-162.

Infante, M. (2015). Proyección Estratégica de la facultad de Ingeniería Industrial para el curso 2015-2016 (Informe presentado). Universidad Tecnológica de La Habana José Antonio Echeverría, La Habana, Cuba.

Kinsumba, P. (2017). Un modelo para la predicción del éxito académico de estudiantes de primer año de la carrera de Ciencias de la Computación de la Universidad Agostinho Neto de la República de Angola (Tesis doctoral). Universidad Tecnológica de La Habana José Antonio Echeverría, La Habana, Cuba.

Kinsumba, P., Lau, R. y Becerra, M. J. (2017). Análisis de factores relacionados con el éxito académico en la Universidad Agostinho Neto. Luz, 71(3), 4-15.

López, Y., Martínez, H., Vilalta, J., y Espinosa, Y. (2014, diciembre). Minería de Datos Educacionales para la inserción de estudiantes en proyectos de desarrollo de software en la UCI: Una revisión. Ponencia presentada en el Simposio Internacional de Ingeniería Industrial y Afines, Memorias de la 17 Convención Científica de Ingeniería y Arquitectura. CUJAE, La Habana, Cuba.

Milán, M. R., Ruiz, H., y Fraga, E. (2013, febrero). Análisis y proyección de algunos indicadores de calidad en la formación de profesionales en Cuba. Ponencia presentada en el Congreso Internacional Pedagogía 2013, La Habana, Cuba.

Ministerio de Educación Superior. (2017). Resolución 111. Reglamento de Organización Docente de la Educación Superior. Recuperado de https://www.udg.co.cu/images/Noticias/Info-web/Resolucion-No-111-2017Reglamento-Org-Docente-22-09-17.pdf

Ministerio de Educación Superior. (2018). Resolución 2. Reglamento de Trabajo Docente y Metodológico de la Educación Superior. Recuperado de https://instituciones.sld.cu/faenflidiadoce/files/2018/08/Resolución-2del-2018.pdf 
Parra, C. M., Mejía, L. F., Valencia, A., Castaneda, E., Restrepo, G., Usuga, O., y Mendiza, R. (2012). Rendimiento académico de los estudiantes de primer semestre de Pregrado de la Facultad de Ingeniería de la Universidad de Antioquia: cohorte 2012-2. Ingeniería \& Sociedad, 2-10. Recuperado de http://bibliotecadigital.udea.edu.co/bitstream/10495/7738/1/ParraCarlos_2013_rendimientoacademicoprime rsemestre.pdf

Quintana, I., y Stive, K. (2015). Análisis del proceso de formación profesional a través de técnicas estadísticas (Trabajo de diploma). Universidad Tecnológica de La Habana José Antonio Echeverría, La Habana, Cuba.

Secretaría Docente. (2016). Informe Docente de la Facultad de Ingeniería Industrial. Universidad Tecnológica de La Habana José Antonio Echeverría, La Habana, Cuba.

Secretaría Docente. (2017). Informe Docente de la Facultad de Ingeniería Industrial. Universidad Tecnológica de La Habana José Antonio Echeverría, La Habana, Cuba.

Soria-Barreto, K. y Zúñiga-Jara, S. (2014). Aspectos Determinantes del Éxito Académico de Estudiantes Universitarios. Formacion Universitaria, 7(5), 41-50.

Urrutia, M. E., Ortiz, S., Fouilloux, C., Ponce, E. R., y Guevara, R. (2014). El rendimiento académico en el primer año de la carrera de médico cirujano: modelo multivariado explicativo. Gaceta Médica de México, 150(3), 24-30.

Vilalta, J., Heredia, J., y Flores, A. (2012). Procedimiento para mejorar las decisiones del proceso docente a través del análisis de datos. Ponencia presentada en XVI Convención de Ingeniería y Arquitectura. CUJAE, La Habana, Cuba.

Zeegers, P. (2004). Student learning in higher education: a path analysis of academic achievement in science. Higher Education Research and Development, 23(1), 35-56.

\section{Contribución autoral}

a) Concepción y diseño del trabajo; b) Adquisición de datos; c) Análisis e interpretación de datos; d) Redacción del manuscrito; e) revisión crítica del manuscrito.

J. A. V. A. ha contribuido en a, b, c, e.

M. J. B. A. ha contribuido en c, d, e.

R. L. F. ha contribuido en c, d, e.

\section{Editora científica responsable}

Mag. Florencia Deleon 